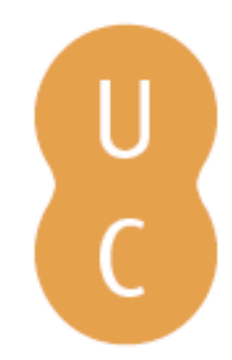

\title{
pommalina
}

\section{Pedagogia e didáctica do homem novo: outra retórica para uma nova sociedade}

\author{
Autor(es): $\quad$ Rei, J. Esteves \\ Publicado por: Imprensa da Universidade de Coimbra \\ URL \\ persistente: $\quad$ URI:http://hdl.handle.net/10316.2/38966 \\ DOI: $\quad$ DOI:http://dx.doi.org/10.14195/978-989-26-0395-7_20
}

Accessed : $\quad$ 26-Apr-2023 01:28:27

A navegação consulta e descarregamento dos títulos inseridos nas Bibliotecas Digitais UC Digitalis, UC Pombalina e UC Impactum, pressupõem a aceitação plena e sem reservas dos Termos e Condições de Uso destas Bibliotecas Digitais, disponíveis em https://digitalis.uc.pt/pt-pt/termos.

Conforme exposto nos referidos Termos e Condições de Uso, o descarregamento de títulos de acesso restrito requer uma licença válida de autorização devendo o utilizador aceder ao(s) documento(s) a partir de um endereço de IP da instituição detentora da supramencionada licença.

Ao utilizador é apenas permitido o descarregamento para uso pessoal, pelo que o emprego do(s) título(s) descarregado(s) para outro fim, designadamente comercial, carece de autorização do respetivo autor ou editor da obra.

Na medida em que todas as obras da UC Digitalis se encontram protegidas pelo Código do Direito de Autor e Direitos Conexos e demais legislação aplicável, toda a cópia, parcial ou total, deste documento, nos casos em que é legalmente admitida, deverá conter ou fazer-se acompanhar por este aviso.

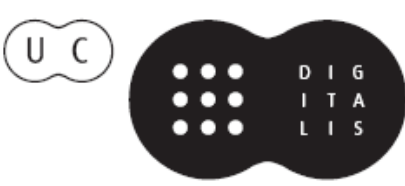


Nair de Nazaré Castro Soares

Santiago López Moreda

Coordenação

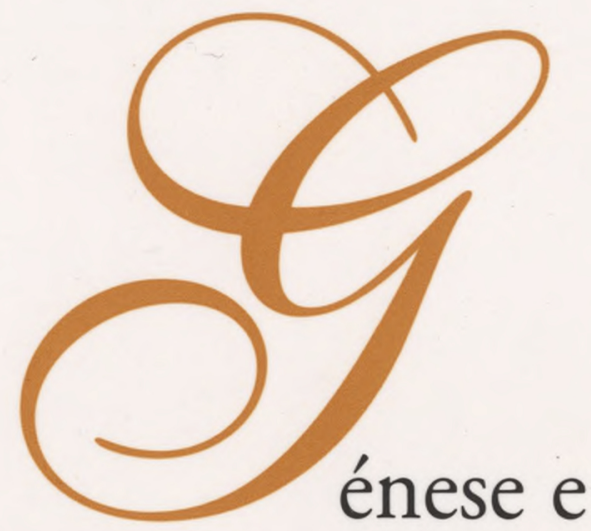

Consolidação da Ideia de Europa

Vol. IV

Idade Média e Renascimento

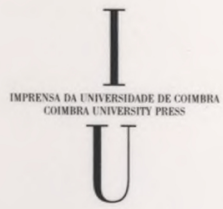

- COIMBra 2009 


\title{
PEDAGOGIA E DIDÁCTICA DO HOMEM NOVO: Outra retórica para uma nova sociedade
}

\author{
J. ESTEVES REI \\ (Universidade de Trás-os-Montes e Alto Douro)
}

Vimos defendendo duas posições relativamente à retórica que, neste texto, se apresentam como pressupostos. A primeira é a de que esta disciplina evolui no tempo e constitui uma unidade desde a Antiguidade Clássica até ao nosso tempo. A segunda, decorrente da anterior, é a de que não se verifica qualquer morte ou ressurreição da retórica, mas, antes, se constituem três retóricas concomitantes, desde que surge uma nova, devendo-se esta ao surgimento de substanciais alterações na sociedade, as quais se repercutem na nossa disciplina e na escola. Estes são os ângulos do triângulo retórico que na sua tripla configuração dá conta da evolução histórica da Grécia até aos nossos dias.

Neste artigo ${ }^{1}$, abordamos aquela que denominámos segunda retórica, "romântica" ou a retórica literário-cultural.

\section{A SOCIEDADE}

As mudanças sociais verificadas nos séculos XV e XVI são produto da conjugação de uma série de factores ou acontecimentos como a formação do "Estado burocrático e centralizado de matiz mercantilista" (Godinho, 1963 I: 11), o regime político baseado no absolutismo, o papel crescente da imprensa, a renovação e autonomia das práticas filosóficas, culturais e científicas, tal como a questão religiosa, isto é, a Reforma e a Contra-Reforma.

Por outro lado, o homem do Renascimento vê-se fustigado por uma série de experiências, viagens, intercâmbios culturais, na Europa e fora dela, envolve-se

1 Este artigo é subsidiário do desenvolvimento que damos ao tema em Retórica e Sociedade, Lisboa, IIE, 1998. 
em grupos e clubes de elites à procura apaixonada de "certezas religiosas e intelectuais, que conduzem a uma renovação espiritual de que saem o Humanismo, as reformas religiosas, a Renascença”" (Corvisier, 1977 III: 25). Por último, a fachada atlântica da Europa lança-se na grande empresa das Descobertas, criando o comércio mundial e impondo a nova concepção do mundo (Corvisier, 1977 III: 25-26).

Surge, assim, o Estado moderno, apoiado em duas figuras, o nobre e o burguês, das quais vão sair os oficiais que servem o rei tanto na governação central como na administração provincial e colonial: desde a cobrança de impostos e a administração da justiça ao serviço no exército.

O poder continua centrado na realeza, tornando-se mesmo absolutista e tendo a sua doutrina sido desenvolvida por Maquiavel que, retoricamente, perguntava: "Que é um governo, senão o meio de dominar os súbditos?" (Almeida, 1969: 25). Nestas circunstâncias, a política assenta mais na técnica que na explicação e, longe de qualquer vivência democrática ela não dá azo a "qualquer discussão acerca dos seus valores e dos seus fins" (Almeida, 1969: 25).

Surge um novo tipo de homem, o cortesão, cujo ideal Baldassare Castiglione (1478-1529) tentou encarnar e deixou consagrado em $O$ Cortesão, ao qual os italianos chamam "o livro de ouro". "O cortesão é um homem senhor de si, de elegância comedida e mesmo grave, antes de tudo afável e educado, desportivo, instruído e cuja conversação está isenta de pedantismo e grosseria." (Corvisier, 1977 III: 56)

Também a questão da Reforma e a correspondente Contra-Reforma, mais do que uma simples oposição religiosa, reflectem realidades profundas da época. Com efeito o descrédito no poder salvífico das indulgências, a interiorização da religião, o divórcio entre a fé e a ciência, conduzem a uma secura de vida que deixa o homem do Renascimento insatisfeito.

Deste modo, vemos surgir o apego à Escritura como fonte de verdade, rejeitando a tradição católica e erigindo, assim, a Bíblia como o fundamento único da crença - o que é facilitado pela invenção da imprensa e pelas numerosas traduções nas línguas vulgares. Este retorno à Bíblia, influi e beneficia da interiorização da religião e, entre os humanistas, do método crítico de leitura de Lorenzo Valla, conduzindo ambos à crença na salvação pela fé, ao desprezo das acções individuais e à livre interpretação das Escrituras.

Ora a simpatia pelas novas ideias, mais próximas ou mais afastadas da Reforma, levou a que durante a primeira metade do século XVI, toda a Europa tenha sido varrida por uma onda de colégios, a maior parte deles municipais, cujos corpos directivos eram recrutados de entre "humanistas errantes muitas vezes influenciados pelas 'novidades luteranas' e os colégios tornaram-se rapi- 
damente verdadeiras fortalezas protestantes" (Mesnard, in Chateau, 1956: 63). Estamos, assim, perante uma consolidação da Reforma, por toda a Europa, a qual, depois de se ter instalado nas instituições político-religiosas, alargava a sua influência às instituições pedagógicas, particularmente às universidades.

A acção de contra-reforma nessa área é entregue aos inacianos, os quais, uma vez chegados a Roma, para se colocarem à disposição do Papa, são encaminhados para a pedagogia e a missionação. A estratégia é rentabilizar a sua formação intelectual, adquirida em Paris, para conferenciar em defesa da ortodoxia doutrinária precisamente entre a juventude, nos colégios.

\section{A RETÓRICA}

Qual o papel reservado à retórica na sociedade que, brevemente, caracterizámos? A retórica foi sobretudo agente de mudança, tendo recuperado até algum espaço de que andava arredada e tendo obrigado a Dialéctica a deslocarse, devido ao carácter pragmático do discurso retórico. Com efeito, a busca da verdade torna-se uma aguda questão individual, deixando de lado o caminho da disputatio medieval e da imposição seca dos dogmas, isto é, do raciocínio dialéctico, e optando pela laboriosa conquista pessoal, onde é indispensável o recurso ao raciocínio retórico, o entimema, recomendado pela sua aplicabilidade a situações práticas e pelo seu aspecto atraente (Orvieto, in Gravelli, 1991: $51)^{2}$. A Retórica vê regressar da Gramática o estudo das figuras, que aí permanecia desde Donato, liberta-se da tipologia imposta pela Idade Média, ouve o apelo ao desenvolvimento da elocutio, isto é, da expressão, e, sobretudo, vê-se integrada na ciência civil pelos "mais famosos pedagogos do século XVI", representando "o auge da formação integral do homem" (Orvieto, in Gravelli, 1991: 51). De facto, ela vai estar na origem de uma das maiores revoluções culturais do Ocidente - a cultura literário-pedagógico-didáctica, tendencialmente alargada às massas (Vico, in Gravelli, 1991: 54).

Portanto, não só não perde terreno, neste período, como inicia um alargamento da sua influência que, provavelmente, até hoje, ainda não parou: ela torna-se o palco de representação-acção já não apenas do orador, mas também do literato-intelectual-escritor. Este, abraçando decidadamente a língua nacional

2 Como observa Orvieto (in B. M. Gravelli, op. cit., p. 51): "o verdadeiro bem do homem é a verdade que consiste [...] numa fatigante conquista pessoal; esta implica primeiramente $o$ domínio da eloquência, e, mais ainda, a reconquista da poesia [...]. Só pela valorização da elocutio, pela leitura dos textos e pela assimilação da grande tradição poética, poderá o homem restabelecer a ligação entre res e verba". 
e nesta desenvolvendo os géneros escritos em prosa, quer ser ouvido por reis e súbditos a quem pretende "agradar, instruindo" (Ménager, 1968: 24-28). Estamos perante o desenvolvimento dessa nova realidade, mais tarde apelidada, como já referimos, de "literatura", seja sob a forma de ficção - talvez a mais frequente - seja sob a forma de relato histórico, seja, ainda, sob essa forma estranha, na época, de ensaio, como foi o caso de Montaigne, a qual assenta fundamentalmente sobre a leitura, o prazer dela extraído e a instrução daí decorrente, procurada quer pelo escritor quer pelo leitor. ${ }^{3}$

A ficção era o espaço de reflexões psicológicas e morais onde mesmo o público mais culto procurava o prazer e a instrução, como acontecia com o Amadis de Gaula "um dos maiores sucessos de livraria do tempo" (Ménager, 1968: 22). Tal como, mais tarde, para os clássicos, já no século XVI, aquilo que contistas e romancistas procuram é "simplesmente o prazer do leitor. Como a conversação, a literatura tem esta função importante de recrear e de divertir." (Ménager, 1968: 28) A literatura, nessa época, é ainda vista por L. Lebvre como uma forma de "passar o tempo e de matar o aborrecimento ameaçador" (Ménager, 1968: 28). Todos os escritores pactuam com os romances de aventuras, mesmo aqueles que atribuíam à literatura uma missão mais elevada. Entre as razões deste facto, encontram-se aquelas que dizem respeito "ao valor moral destas obras" (Ménager, 1968: 28). ${ }^{4}$

O relato histórico reivindica nesta época, ao lado do estatuto literário, "que o distingue - pelo menos em princípio - dos escritos poético-romanescos" (Wolff, 1988 II: 87-88), outros títulos de nobreza: o dizer-verdadeiro e o bemdizer, cujo estilo pode sumariamente ser apresentado por duas palavras: liber-

3 "A leitura foi [na época] para muitos o que ela é ainda hoje: um meio de evasão e de arejamento de ideias" (D. Ménager, op. cit., p. 21). O que atraía os leitores, particularmente os pertencentes ao público mais popular, nessas epopeias feudais eram "os seus episódios movimentados, as proezas dos seus heróis, os seus encantadores e os seus mágicos, a sua cómica ou a sua franca sentimentalidade", H. Coulet, (ibid.). Por outro lado, não havia um único escritor deste século que não se propusesse, de um modo ou de outro, a instrução dos seus semelhantes" (ibid., p. 29).

${ }^{4}$ Ibid. No desenvolvimento desta ideia, o autor recorre à autoridade de Jodelle - que explica a pedagogização desta nova retórica - quando escreve: "Os falsos combates, as falsas vitórias, quando se descrevem com bravura, (podem) moldar e encorajar a juventude tão bem como os mais verdadeiros acontecimentos de armas". Conviria lembrar a primeira reflexão pedagógica relativa à leitura dos poetas realizada pelo grande filósofo-pedagogo greco-romano, Plutarco (em "Comment il faut que le jeune homme écoute la lecture des poètes", in Plutarque, Oeuvres Complètes et Oeuvres Diverses, Trad. Victor Bétolaud, Paris, Librairie Hachette, 1870) precisamente no momento em que os imperadores Flávios criavam a escola pública e era necessário ensinar a ler essa quantidade cada vez maior de cidadãos que acorriam às escolas. 
dade e leveza ou elegância. O primeiro aspecto tem a ver com a independência do formalismo estrutural, temático e estilístico - colocando em questão o primeiro passo da retórica clássica, a invenção; o segundo, diz respeito às prioridades impostas e às modalidades diversas, segundo os géneros e os meios sócio-culturais aos quais o bem-dizer deve adaptar-se. O historiador, tal como $o$ escritor, como já vimos, sente-se investido de uma missão, a de agradar e instruir, o que faz da história "o lugar de um ensino, de uma pedagogia. O 'sabor de doutrina', de cavaleiresco e de heróico que ela [a história] tinha, orienta-se deliberadamente para o comentário moral, religioso e político." (Wolff, 1988 II: $95,91)$ É que a história é, como escreve o nosso João de Barros, um campo "onde está semeada toda a doutrina divinal, moral, racional e instrumental" (Saraiva e Lopes, 1976: 296) que, na expressão de A. José Saraiva e Óscar Lopes, "serve para alimentar a memória e o entendimento dos homens e leválos a uma "justa e perfeita vida", sendo estas últimas palavras do autor das Décadas. Paralelamente, a originalidade do historiador alastra ao estilo em que elabora o comentário, a narração ou a descrição - "a invenção está na forma: o vocabulário, com os seus latinismos [...], as comparações eruditas, as frases com cadências regulares e ritmos estudados" (Wolff, 1988 II: 102).

Um outro género literário e outro autor se apresentam, neste período, como angariadores de novos espaços para a retórica: trata-se do ensaio, criado por Montaigne. Este facto é, aparentemente, tanto mais anacrónico quanto "Montaigne nunca perde ocasião de verberar o gosto da retórica, dos jogos de palavras que servem apenas para dissimular falta de pensamento" (Silva, in Montaigne, 1993: 80). É verdade que este autor é um crítico acérrimo da retórica clássica pois, como afirma, "Contanto que o nosso discípulo esteja bem provido de coisas, não the hão-de faltar as palavras: se não vierem a bem, virão a mal." (Silva, in Montaigne, 1993: 80) Montaigne, porém, é um criador de novos espaços retóricos, portanto, da retórica do ensaio, que delimita desta forma: "Quero que as coisas venham ao de cima e que encham de tal modo a imaginação daquele que escuta que não se ponha a pensar nas palavras. A linguagem de que gosto é uma linguagem simples e natural, igual no papel e na boca; uma linguagem suculenta e nervosa, breve e cerrada, não tanto delicada e louçã como veemente e brusca. [...] antes difícil do que aborrecida, fora de afectação e de regras, descozida [sic], audaciosa; cada pedaço deve valer por si próprio; nem pedantesca nem fradesca, nem tribunalesca, antes soldadesca, como Suetónio chama à de Júlio César, embora eu não saiba muito bem porquê [...]. Não gosto de composição em que apareçam ligações e costuras, do mesmo modo que num corpo bem feito se não devem poder contar os ossos e as veias." (Silva, in Montaigne, 1993: 80) Relativamente à caracterização literária 
deste novo género, ouçamos a palavra pertinente de Eduardo Lourenço, esse exilado cultural na terra de Montaigne: "Poucos escritores se podem gabar de ter inventado um género literário [...]. Mas a invenção do 'ensaio' não é apenas um acontecimento de ordem literária, um achado feliz, entre outros, a colocar ao lado da 'confissão' ou das 'cartas'. Consideram-se, com justiça, os Ensaios como o lugar escrito ou o diário de bordo de uma aventura mais inaudita ainda que a de Colombo: a da descoberta do Homem como a sua própria América [...]. Na verdade, o escândalo reside aqui: Montaigne, desculpando-se com a sua 'boa fé' perante o leitor, oferecia-lhe, pura e simplesmente, esta coisa sem nome, mais incontrolável e desestabilizadora que todas as invenções humanas, que mais tarde se chamará Literatura. Sob a sua forma mais irresistível, aquela que o não merece por se apresentar, sem ser por conhecida estratégia retórica, como 'não-ficção'." (Lourenço, 1992: 40-41)

Esta segunda retórica, "romântica" ou literário-cultural, cujo período inaugural, no século XVI, acabamos sucintamente de caracterizar situa-se já não na esfera das necessidades do indivíduo, está ao serviço já não de cidadãos singulares, actores linguístico-retóricos ou seus clientes, mas da cultura que, por sua vez, passa a prestar um relevante serviço à política ${ }^{5}$. Três são os factores determinantes desta mudança: a deslocação da cultura das universidades e mosteiros para um público mais vasto, concentrado "nas cortes dos novos príncipes, mas também nos palácios comunais, nas residências burguesas, nas pequenas escolas de retórica e até penetrara nos atelieres artesanais [e que] suscitara, cada vez mais claramente, formas diferentes de comunicação e de expressão" (Garin, 1972: 71); a vulgarização da língua nacional por filósofos, escritores, historiadores e sábios, dando-se até o caso de "Giannozzo Manetti ou

5 "A cultura é uma componente importante da política. Daí o peso que toma a exigência de a difundir fora do círculo dos profissionais do saber: exigência que se concretiza no carácter cívico desta cultura; que se manifesta sob as formas e géneros literários; que se traduz institucionalizando-se nas escolas e nas 'academias'; que se manifesta numa palavra em livros, primeiro pela multiplicação dos manuscritos, depois pela descoberta da tipografia, na Alemanha, e pelo seu desenvolvimento rápido, na Itália e em toda a Europa. Não se trata, pois, de nenhum acaso, se no dealbar do século XVI, os próprios impressores se transformam em núcleos de reagrupamentos culturais importantes." Eugénio Garin, O Renascimento. História de uma Revolução Cultural, Porto, Telos Editora, 1972, p. 72. Este autor (op. cit., p. 93) afirma ainda: "A cultura [s.n.] é um instrumento precioso para viver e brilhar nas novas cortes, para atrair a benevolência das damas, para progredir na carreira política, para assumir cargos militares. De elemento substancial que eram, as 'letras' tendem cada vez mais a transformar-se em elemento formal, ao serviço de exigências públicas concretas, intervindo na vida de grupos sociais determinados." Este novo estatuto das "letras" e da cultura, ou seja, da retórica, vai ser directamente visado pela nova escola da época, o colégio renascentista. 
um filósofo como Marsílio Ficino, escreverem muitas das suas páginas ao mesmo tempo em Latim e em volgare" (Garin, 1972: 71-72); e, por último, a rápida expansão da imprensa.

Definida desde sempre como a arte de persuadir, a verdade é que a retórica sempre alargou a sua influência a outros modos de falar - facto a que poderíamos bem chamar de equívoco retórico. Isto começa a verificar-se, de modo claro em Roma, com as escolas estatais de retórica implantadas por Quintiliano, tornado pelo imperador autêntico Ministro da Instrução. Contudo, esse equívoco acentua-se a partir do século XVI, com a diversificação das necessidades sociais às quais ela deve acorrer. Deste modo, vemos o Prof. Anibal Pinto de Castro afirmar que "A Retórica, embora definida muitas vezes apenas como a arte de bem falar, dava preceitos para todos os géneros em prosa, dos sermões às cartas, passando pelos discursos académicos, pela historiografia, pela novela e pela prática oral. A própria poesia não lhe ficava estranha." (Castro, 1973: 8)

A retórica torna-se assim indispensável para a entrada dos alunos na Universidade onde adquire um espaço cada vez maior. Essa institucionalização cultural da Retórica deve-se ao facto de "o ensino deixa[r] de ter uma finalidade estritamente profissional" (Carvalho, 1986: 155), o que quer dizer que uma larga faixa da população, letrados e profanos, de profissões diversas, olha para o ensino, o mesmo é dizer, para a Gramática, para a Poética e para a Retórica, como instrumentos indispensáveis à vida comunitária, mas também individual ou pessoal. Com efeito, "o conhecimento da leitura e da escrita não é já, como outrora, uma simples introdução aos estudos jurídicos ou clericais, mas um instrumento indispensável aos numerosos agentes do comércio internacional, às comunicações a longa distância, que se multiplicavam, ao conhecimento da legislação escrita, cada vez mais volumosa e variável [...], às grandes concentrações urbanas em crescimento." (Saraiva, 1955: 155) Essas necessidades alargavam-se a um elevado número de pessoas, na dependência dessa burguesia comercial, e, ainda, à própria vida cortesã na qual B. Castiglione, no início do século XVI, exigia a presença de um cortesão "versado nos poetas e não menos nos oradores e historiadores e ainda exercitado em escrever verso e prosa" (Saraiva, 1955: 157).

Entre nós, a Retórica e a Poética, com a introdução da pedagogia renascentista no Colégio Real das Artes, tomam o lugar da Filosofia Aristotélica, particularmente a Dialéctica, "na formação cultural dos candidatos às Faculdades universitárias" por serem "as únicas disciplinas capazes de fazerem desaparecer a secura bárbara da escolástica medieval" (Castro, 1973: 28). Prova disto 
é o facto de metade dos 16 docentes do Colégio serem professores de Gramática, Retórica e Poética. A função da Retórica, segundo o Mestre Arnaldo Fabrício, ao pronunciar a Oração da solene abertura, e nas palavras de A. Pinto de Castro, é "uma função de comunicação social, docente e moralizadora" (Castro, 1973: 30-31). A razão avançada por esse nosso seiscentista estava no facto de nenhuma outra arte ou ciência estar tão presente na vida dos homens: da paz e amizade entre os povos à instrução das cidades, dos reinos e impérios à elaboração das leis, ao cumprimento das sentenças e à libertação dos oprimidos, da descoberta dos enganos e dos crimes à vingança das ofensas.

Apoiada nas línguas, Latim, Grego e Hebraico, a Retórica vê-se, no Renascimento, inserida numa concepção global de cultura e educação que contrasta fortemente com a da escolástica, reinante nas Universidades. Na verdade, essas disciplinas são vistas como a porta para o conhecimento da Antiguidade: a literatura e a cultura, mas também a história e a ciência. O objectivo perseguido é, na expressão de A. J. Saraiva, "substituir por uma interpretação filológica, histórica e crítica, o comentário tradicional do texto bíblico, formalista e dogmático" (Castro, 1973: 160). São duas as vias de influência da nossa disciplina: 1) a formação do espírito do escritor pelo fornecimento de um conjunto de regras, definições e esquemas formais; 2 ) a modelagem do espírito crítico do leitor por esse mesmo conjunto de regras, definições e esquemas. Deste modo, a retórica preside à produção discursiva e condiciona a leitura. Ao amenizar a secura do silogismo dialéctico, ao aumentar a dimensão literária da própria eloquência, ao trazer os textos originais dos autores antigos e ao acrescentar um modo claro, elegante e atraente de comunicar as matérias, "desprendia-se cada vez mais da madre Filosofia, para se manifestar numa teoria da prosa" (Castro, 1973: 32).

\section{A ESCOLA}

A escola correspondente à sociedade e à retórica estudadas tem entre os seus precursores Vittorino de Feltre (m. 1446) que, em Mântua, fundou o primeiro liceu humanista para os filhos de famílias insignes e da classe rica, isto é, os filhos e as filhas da aristocracia, cujo modelo foi imitado em toda a Itália (Macedo, 1989: 35). Do programa, faziam parte tanto uma formação científica como uma preparação linguística e matemática, segundo os cânones da Antiguidade. É deste ambiente que surgirá mais tarde o livro O Cortesão de Baldassare Castiglione, onde se apresenta, em toda a sua plenitude, a imagem do senhor da corte ideal, harmonioso e culto. O objectivo da formação "não se traduzia na transmissão de certos conhecimentos com determinada finalidade, 
antes, pretendia tornar viável a abordagem dos mais diversos campos e a posse de uma cultura o mais universal possível, conforme ao uomo universale [...] como o encarnavam entre outros Leon Battista Alberti e Lorenzo de Valla." (Macedo, 1989: 35) Mais tarde, o termo colégio designará estabelecimentos muito diferentes, desde pensões para alunos das faculdades das Artes até escolas criadas pelas cidades que não tinham universidade. Todavia, o típico colégio humanista do século XVI transforma-se num estabelecimento de ensino, situado entre as escolas elementares e a primeira das faculdades, a das Artes, da qual os estudantes saíam para a vida activa ou passavam às faculdades superiores de Teologia, Direito e Medicina (Corvisier, 1977 III: 52).

Entre nós, foi D. João III quem meteu ombros à tarefa de criar este tipo de colégio, realizada entre 1527 e 1537, no mosteiro de Santa Cruz, em Coimbra, conduzida por Brás de Barros (Carvalho, 1986: 216). Segundo Rómulo de Carvalho, as informações relativas à reforma joanina são "avulsas", dando-nos apenas "uma visão do que poderia ter sido a criação do ensino preparatório" (Carvalho, 1986: 216). Esta primeira tentativa de renovação do ensino secundário fracassou, o que leva o rei à criação de um colégio à imagem dos grandes colégios europeus. Assim nasceu o Colégio Real das Artes, tendo o rei ido mesmo buscar, para seu responsável, o mais categorizado "principal" de França, na expressão de Montaigne (Carvalho, 1986: 243), que era André de Gouveia, Director do Colégio de Guyènne, em Bordéus. É no Regulamento deste colégio, em parte importado de Bordéus e apresentado em 1547, que a Retórica aparece em força, nas três últimas das dez classes do curso de Latinidade que incluía, ainda, o Grego, nas cinco últimas, e o Hebraico. As vicissitudes que envolveram o Colégio depois da morte do seu fundador, em Junho de 1548, quatro meses depois da sua inauguração, revelaram a cisão latente entre os docentes do colégio: os "parisienses", formados em Paris e que já se encontravam em Portugal, e os "bordaleses", que tinham vindo de fora e, como André de Gouveia, eram conotados com a oposição aos colégios e à Universidade da cidade luz, sendo mais tarde em Portugal objecto de "acusação à Inquisição de suspeitos de heresia" (Carvalho, 1986: 258).

Uma das características da escola humanista é o seu surgimento à margem das universidades que, mais tarde, vai mesmo influenciar. Uma outra é a sua abertura não apenas aos filhos das grandes famílias, "mas igualmente a jovens de origem modesta, que por sua vez virão a tornar-se professores ou funcionários públicos" (Carvalho, 1986: 88). Por fim, salientemos as alterações curriculares e metodológicas introduzidas de acordo com as novas funções sociais a desempenhar. Propedêutica da Universidade - ensino superior, em relação ao qual ela constituía um ensino preparatório, isto é, um nível inferior -, 
esta escola estava dividida em ciclos de estudo, dos quais o primeiro, com a duração de quatro anos era também referido como sendo de Humanidades, compreendia o estudo das línguas (Latim, Grego e Hebraico) e das literaturas (Poética e Retórica), concedendo o grau académico de bacharel, de licenciado e de mestre em Gramática e designando-se os respectivos graduados "gramáticos"; e o segundo, ou das Artes, também ele com a duração de quatro anos, incluía a Lógica, as Súmulas (ou "resumos" de Lógica) e a Filosofia.

O objectivo desta escola é a formação do cortesão, cujo ideal já não era "o cidadão de uma república livre, mas sobretudo o homem de corte, ao serviço dum príncipe e seu colaborador, capaz de conversar bem e se comportar bem, de agir e de se impor na sociedade" (Garin, 1972: 93). O que este homem renascentista procurava na escola era o mesmo que procurava nas bibliotecas, nas academias, no livro, agora impresso: "meios de libertação espiritual, conselhos de sabedoria política, bases e métodos para uma visão mais realista da natureza" (Garin, 1972: 93), isto é, do mundo novo e de si próprio nele. Cidadão, homem de ciência, artista, técnico, homem do mundo, funcionário zeloso e outras, eram algumas das muitas saídas para que devia apontar essa formação geral. É que a educação humanista procurava uma totalidade capaz de tornar o homem não apenas apto para tudo, mas para ser, na medida do possível, tudo.

Poder-se-á pensar, até pela origem da maior parte das nossas fontes, que esta realidade referente aos colégios renascentistas se situa lá longe, afastada do que se passa, à época, em Portugal. Contudo, as informações que poderíamos avançar fornecer-nos-iam uma outra ideia. É que, esses colégios, entre nós, não só eram em elevado número como se regiam pelos mais conceituados estabelecimentos de ensino por essa Europa fora, dela recebendo muitos dos seus ilustres mestres e "leitores" de vários cursos e disciplinas, como podemos observar pelo conteúdo de alguns testemunhos acima de qualquer suspeita. É o caso de Nicolau Clenardo, humanista flamengo, mestre notável da Universidade de Lovaina, onde André de Resende foi seu aluno, e que veio para Portugal como professor do Infante D. Henrique, irmão de D. João III, e futuro Cardeal- rei $^{6}$. Esta imagem positiva dos nossos colégios renascentistas tem a suportá-la uma plêiada de mestres nacionais e estrangeiros cujo currículo contempla a frequência, quando não a docência, nos colégios europeus de mais nomeada. É o que acontece com Frei Brás de Barros e Frei Diogo de Murça, enviados por

${ }^{6}$ Este professor, tendo visitado o colégio de Santa Marinha da Costa e assistido a algumas aulas, comunica a sua impressão em carta a pessoa amiga, afirmando: "Assisti às lições de todos eles [professores] e quiseram-me parecer bastante desempoeirados no seu assunto." (Rómulo de Carvalho, op. cit., p. 231). 
D. Manuel para Paris, provavelmente em 1517 e mais tarde graduados em Teologia por Lovaina. Deles trouxeram a formação pessoal, mas também os conteúdos e os métodos, a disciplina, a pedagogia e os ideais da época que bem necessários eram para a renovação que se impunha. Os sucessos destes fortes investimentos pedagógico-didácticos, para além do reconhecimento de alguns estrangeiros como já observámos, parecem ter deixado satisfeitos os seus impulsionadores.

\section{PARA CONCLUIR}

A unidade a partir da tríada sociedade-retórica-escola apresenta-se, assim, como natural na abordagem do devir histórico dessas três realidades. $\mathrm{O}$ triângulo constituído a partir delas permite-nos analisar de forma minuciosa e contínua as configurações concretas que, na nossa perspectiva, se reduzem a três. Noutras abordagens, porém, poderão multiplicar-se em função dos períodos e dos dados recolhidos e em análise. Importantes parecem-nos a pertinência e a relevância do método, a seguir no tratamento a dar aos dados seleccionados e tomados como objecto dessa análise.

BIBLIOGRAFIA

Almeida, Fortunato de, 1969, História da Igreja em Portugal, Porto, Lisboa, Livraria Civilização Editora.

Barros, João de e Murta, Guerreiro, s/d., Como se devem ler os escritores modernos, Lisboa, Liv. Sá da Costa.

Carvalho, Rómulo de, 1986, História do Ensino em Portugal, Lisboa, Fundação Calouste Gulbenkian.

Castro, Aníbal Pinto de, 1973, Retórica e Teorização Literária em Portugal, Coimbra, Centro de Estudos Românicos.

Corvisier, André, 1977, História Universal. O mundo moderno, Círculo de Leitores, Vol. III.

Garin, Eugénio, 1972, O Renascimento. História de uma Revolução Cultura, Porto, Telos Editora.

Godinho, Vitorino Magalhães, 1963, Os Descobrimentos e a Economia Mundial, Lisboa, Editorial Arcádia, Vol. I.

Gravelli; B.M., 1991, Manual de retórica. 
Lorian, Alexandre, 1991, Rhétorique et mise en prose au XVe siècle, Actes du VI Colloque International sur le Moyen Français, Milan, 4-6 Mai 1988, Milão, Vita e Pensiero, Vol. II.: "Pléonasme et périssologie: le récit redondant au $\mathrm{XV}^{\mathrm{e}}$ siècle".

Lourenço, Eduardo, 1992, "Montaigne ou a vida escrita" (in Expresso, Revista, de 12 de Setembro.

Macedo, Jorge Borges de, 1989, História Universal, (adapt. e rev.), Círculo de Leitores e Bertelsmann Lexikothek Velag Gmbh, Vol. III.

Ménager, D., 1968, Introduction à la Vie Littéraire au XVI Siècle, Paris, Bordas.

Orvieto vide Gravelli, B. M..

Plutarco, 1870, Oeuvres Complètes et Oeuvres Diverses, Trad. Victor Bétolaud, Paris, Librairie Hachette: "Comment il faut que le jeune homme écoute la lecture des poètes".

Saraiva, António José e Lopes, Óscar, 1976, História da Literatura Portuguesa, Porto, Porto Editora, $9^{\mathrm{a}}$ ed.

Silva, Agostinho da, in Montaigne, Três Ensaios, Lisboa, Vega, $2^{\mathrm{a}}$ ed.

Wolff, Hélène, 1991, "Prose historique et rhétorique. Les Chroniques de Chastelain et Molinet", in Rhétorique et mise en prose au XVe siècle, Actes du VI Colloque International sur le Moyen Français, Milan, 4-6 Mai 1988, Milão, Vita e Pensiero, Vol. II. 